Fourth International Conference on Sustainable Construction Materials and Technologies http://www.claisse.info/Proceedings.htm

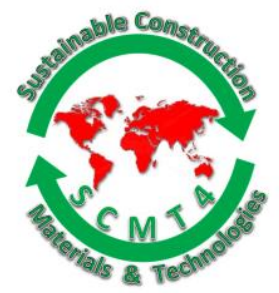

SCMT4

Las Vegas, USA, August 7-11, 2016

\title{
Improvement of Durability of Recycled Asphalt Mixture Using Developed Anti-Stripping Agents
}

\author{
Woo-Jin Seo'a , Dae-Wook Park*1b, Hai Viet Vo ${ }^{1 \mathrm{c}}$, and Hyeok-Jung Kim² \\ ${ }^{1}$ Department of Civil Engineering, Kunsan National University, KOREA. ${ }^{\text {la Email: }}$ \\ <seowoojin@kunsan.ac.kr>, ${ }^{* 1 b}$ Email : <dpark@kunsan.ac.kr>, ${ }^{1 c}$ Email :<haivo2310@gmail.com>. \\ ${ }^{2} R \& D$ Center, Kumho Petro Chemical Co., KOREA, ${ }^{2}$ Email: <ceasare@kkpc.com>.
}

\begin{abstract}
In this study, anti-stripping agents were developed to improve the moisture susceptibility of recycled asphalt mixture. As a screening test of moisture susceptibility of asphalt mixture, boiling water test was conducted. The stripping ratio was measured by counting the number of stripped aggregate particles in the boiling water test according to ASTM D3625. Based on screening test results, best performance anti-stripping agents were selected and the indirect tensile strength ratio (TSR) was used to evaluate the moisture susceptibility of asphalt mixture and test specimens were conditioned according to Korea Standard (KS) F 2398. For comparison purpose, different asphalt mixtures which are contained limestone, fly ash, desulfurization gypsum and anti-stripping agents were evaluated using TSR values. Also, Hamburg wheel tracking test was conducted to evaluate the moisture susceptibility and rutting resistance of asphalt mixtures contained anti-stripping agents.

The results showed that asphalt mixtures contained developed anti-stripping agent have significantly higher or equal TSR values than hydrated lime, fly ash, and desulfurization gypsum. Also, the asphalt mixture contained desulfurization gypsum showed higher TSR value than asphalt mixture contained fly ash. Hamburg wheel test results showed that asphalt mixture contained the developed anti-stripping agent was higher moisture susceptibility and rutting resistance than asphalt mixtures contained hydrated lime and commercialized anti-stripping agent.
\end{abstract}

\section{INTRODUCTION}

The moisture damage causes loss of adhesion, and adversely affect to the strength of the asphalt mixture dramatically. It can also cause the premature pavement failures such as rutting and raveling on the pavement surface [Taylor and Khosla 1983; Solaimanian et al. 1993]. Moisture sensitivity testing has been applied by many agencies in the asphalt mixture design stage and the result of this testing can be used to eliminate certain asphalt and aggregate combinations or to investigate the needs of an anti-stripping additive. The 
potential to incur moisture damage can be controlled or reduced by material selection, mixture designs, increasing a high asphalt film thickness, additives, proper pavement design, compaction, and drainage [Little and Epps 2001]. Solaimanian et al. [2003] suggest that the most common technique to mitigate moisture damage is the use of additives or modifiers with the asphalt binder or the aggregate, and AASHTO T-283 is a widely recognized laboratory test method for the evaluation of moisture susceptibility. Al-Qadi et al. [2014] summarized that developing laboratory moisture damage evaluation tests is challenging and it is hard to simulate field performance because of the high variability of the factors affecting moisture damage and the process of developing new test procedures still continues. Rahman [2012] evaluated the performance-based properties of asphalt mixtures using two different lime application processes, adding dry hydrated lime to wet aggregate and adding lime slurry to dry aggregate. The author found that the application of hydrated lime in asphalt binder is an effective and economical method to evaluate moisture damage as well as rutting. The Hamburg wheel tracking test (HWTT) has been widely used as a standard laboratory test to evaluate mixture moisture susceptibility and rutting resistance. Yin et al. [2013] introduced a novel method to analyze HWTT results and three new parameters were proposed to quantify mixture moisture susceptibility before and after stripping occurred and rutting resistance. The new test parameters demonstrate significant advantages in characterizing mixture resistance to stripping and rutting in the HWTT. Walubita et al. [2016] suggested that the newly derived HWTT data analysis parameters, with considering the rutting path-history, yielded promising results for predicting the early-life rutting performance of the HMA mixes.

The purposes of this study are to comprehensively evaluate the moisture susceptibility of asphalt mixtures modified with several anti-stripping additives based on several tests. The works include conducting screening test (boiling water test), and indirect tensile strength (ITS) test based on ASTM D3625-96 and KS F 2398, respectively on specimens prepared with different additives. HWTT protocol of the Tex-242-F specification is performed and the data are analyzed by new methodologies to evaluate moisture susceptibility and rutting resistance of the asphalt mixtures.

\section{MATERIALS}

Asphalt binder and aggregate are the main components in asphalt mixture. The aggregates represented materials currently in production for hot mix asphalt with an addition of recycle asphalt pavement (RAP) of 30 percent. The combined aggregates and RAP were used to meet the required aggregate distribution. Asphalt binder PG58-22 grade was used as controlled binder.

The additives limestone (L), fly ash (F), desulfurization gypsum (DG), developed anti-stripping agents (K) numbered from 1 to 7 , and current anti-stripping agent (W), were evaluated in this study. In all cases, the mineral powder limestone was dosed at a rate of 2 percent by weight of aggregates, and the liquid additives were dosed at rates of 0.5 percent by weight of new asphalt binder, with totally 3 replicates for each. Controlled sample $(\mathrm{C})$ was also made for comparison purpose.

\section{TESTING AND DISCUSSION}

Screening test (boiling water test). This test procedure is a quick and simple method for evaluating the moisture sensitivity of an aggregate-asphalt mixture in order to select an expected anti-stripping agent, $\mathrm{K}$. About $500 \mathrm{ml}$ of distilled water is brought to boiling in a 1000-2000 ml glass beaker. Afterwards, the prepared aggregate-binder mix is placed into the boiling water. After $10 \mathrm{~min} \pm 5 \mathrm{secs}$, the mixture is allowed to cool while the stripped asphalt is skimmed away. The water is drained, and the wet mixture is placed on a paper towel and allowed to dry. Visual rating is conducted to assess the level of stripping by the ratio of stripped aggregate particles to the amount of total [ASTM D3625-96 2005]. 


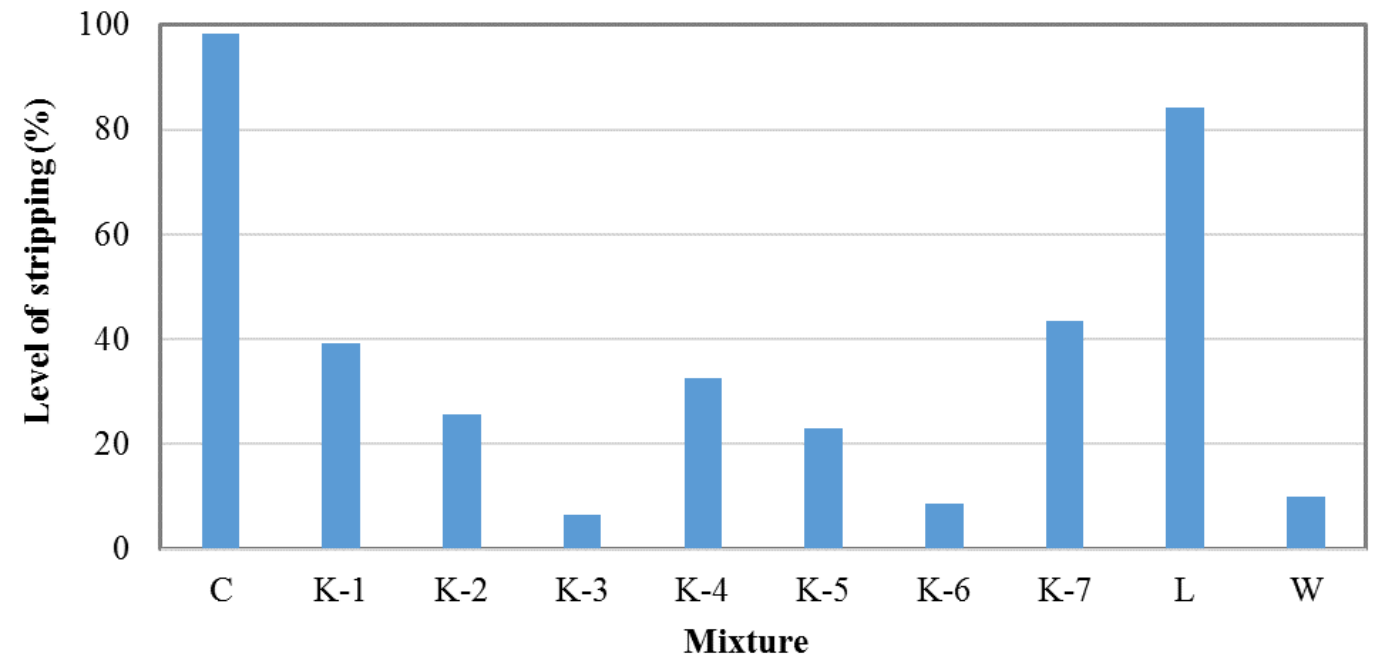

Figure 1. Boiling water test results

In boiling water test, thirty samples were tested in boiling water in order to provide three replicates for each type of mixture. Fig. 1 shows the average results of screening test. The liquid agents are proved to provide positive effect to moisture resistance. Limestone, in this test, shows a drawback with high level of stripping. Samples K-3 were chosen to conduct the next stage of testing due to their lower level of stripping compared to the others.

Indirect tensile strength test. Indirect tensile strength (ITS) test was conducted to investigate the effect of anti-stripping additives on moisture susceptibility characteristic. The damage due to moisture is controlled by the specific limits of the tensile strength ratios (TSR). ITS test was performed according to the KS F 2398 [2012] by compacted specimens of $100 \mathrm{~mm}$ in diameter and $63.5 \mathrm{~mm}$ in height at air voids of $7 \pm 0.5$ percent. The specimens are separated into two subsets, unconditioned subset for dry ITS test and conditioned subset for wet ITS test. For conditioned samples, they were saturated with water to between 55 and 80 percent then placed in a vacuum container filled with water. A vacuum of 13-67 kPa absolute pressure was applied for 5 to 10 minutes. Each sample was wrapped in a plastic bag containing $10 \mathrm{~mL}$ of water and place it in a freezer at $-18^{\circ} \mathrm{C}$ for at least 16 hours. The conditioned samples were thawed in a bath of distilled water at $60^{\circ} \mathrm{C}$ for 24 hours. While the conditioned samples were being conditioned, the unconditioned samples stored at room temperature. A samples were in a $25^{\circ} \mathrm{C}$ water bath for a minimum of 2 hours prior to testing.

ITS test was conducted using indirect tensile strength tester (Fig. 2). During the test, compressive load was applied through two loading strips. The maximum indirect tensile force was recorded and the corresponding ITS of the asphalt mixture was determined. The tensile strength ratio (TSR), a ratio of the ITS of wet conditioned specimens to the ITS of dry specimens, was calculated and used as a moisture susceptibility index of asphalt mixtures. The ITS, $S_{t}$, is calculated using Eq. (1):

$$
S_{t}=\frac{2000 P}{\pi D t}
$$

where, $P=$ the maximum load $(\mathrm{N})$,

$t=$ the thickness of specimen $(\mathrm{mm})$, and

$D=$ the diameter of specimen $(\mathrm{mm})$. 
The TSR values are determined from the dry and wet ITS test results using Eq. (2):

$T S R=\frac{S_{t, \mathrm{w}}}{S_{t, d}}$

where, $S_{t, w}=$ average wet ITS $(\mathrm{kPa})$, and

$S_{t, d}=$ average dry ITS $(\mathrm{kPa})$.

According to Fig. 2(b), the asphalt concrete mixtures containing the additives K-3, L, F, DG, W and C have TSR values of $90.8 \%, 83.6 \%, 78.7 \%, 95.1 \%, 97.5 \%$ and $52.5 \%$ respectively. Accordingly, almost all the mixtures with anti-stripping additive meet the criteria of minimum TSR value of 80\% [KS F 2398 2012], except the one with fly ash. K-3, DG, and W show themselves the most effective anti-stripping agents in improving stripping resistance. Basically, the additives have positive effects on performance and moisture susceptibility of asphalt concrete mixture. However, Harikrishnan [2008] found that the values of dry and wet ITS together with TSR values should all be employed to evaluate the effect of water damages on performance of asphalt concrete mixtures. The anti-stripping additive does not seem to affect the ITS values (Fig. 2(a)).

(a)
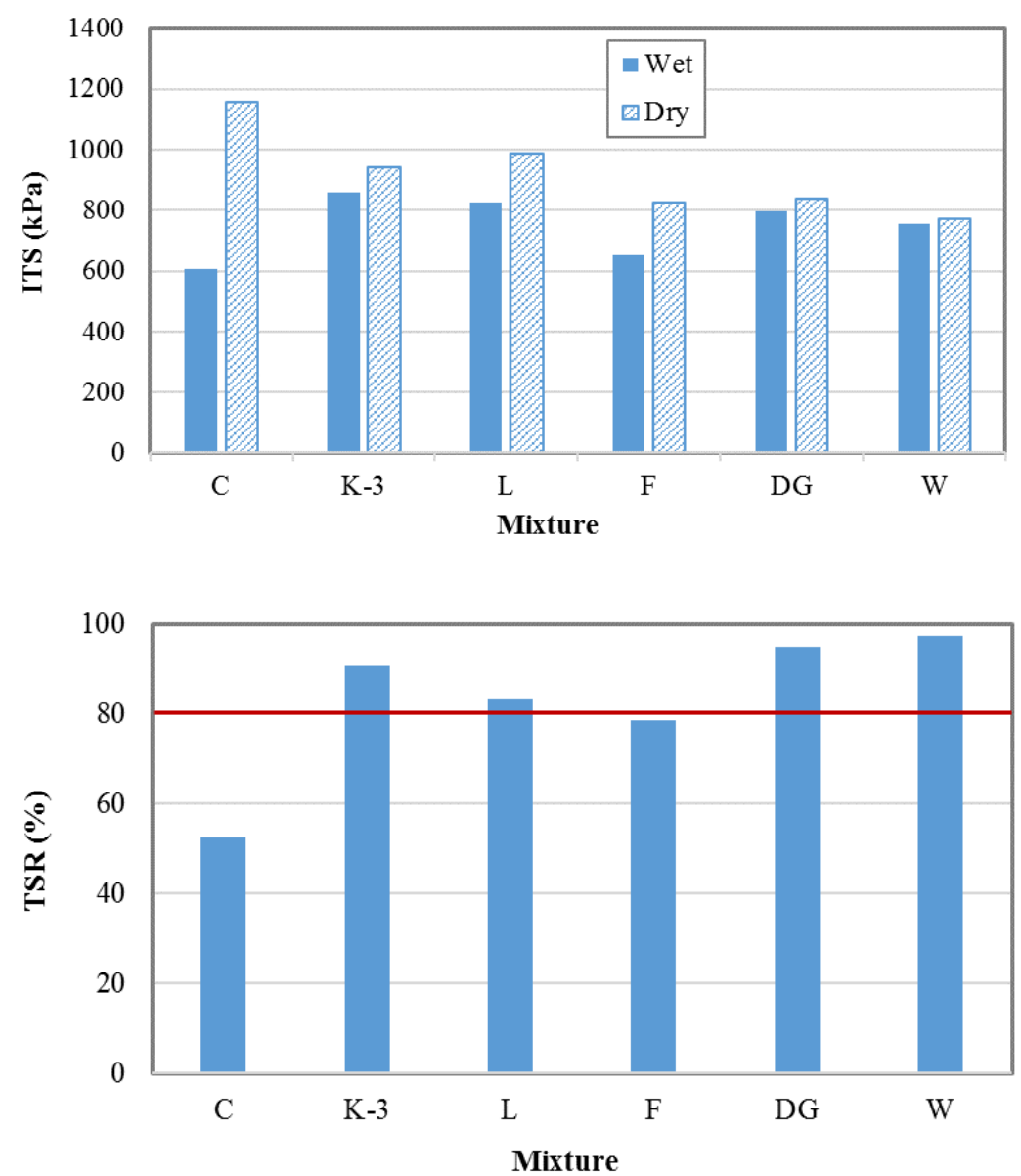

Figure 2. (a) Indirect tensile strength (ITS) and (b) Tensile strength ratio (TSR) results 


\section{HAMBURG WHEEL TEST AND EVALUATION}

Hamburg Wheel Tracking Test (HWTT) was conducted according to Tex-242-F [2014]. Rut depth at a certain number of load cycles and the Stripping Inflection Point (SIP) in the test are widely adopted by several transportation agencies for mixture performance evaluation; however, these parameters do not always provide accurate conclusions based on the behavior of the mixtures during testing. This section covers two methodologies to analyze HWTT data; curve fitting method for moisture susceptibility and rutting resistance evaluation.

In curve fitting method according to Yin et al. [2014], the rut depth versus load cycle HWTT output data is plotted to obtain a typical curve for the test. Then, Eq. (3) is used to model the results.

$R D_{L C}=\rho\left[\ln \left(\frac{N_{d}}{L C}\right)\right]^{-\frac{1}{\beta}}$

Where, $L C=$ load cycles at a certain rut depth;

$N_{d}=$ the maximum number of load cycles reaching $12.5 \mathrm{~mm}$ rutting or 20000 times;

$R D_{L C}=$ rut depth of the HWTT specimen at a certain number of load cycles (mm);

$\rho$ and $\beta=$ model coefficients.

Moisture susceptibility evaluation. The load cycle where the Stripping Number (SN) occurs $\left(L C_{S N}\right)$ is proposed as a parameter to quantify mixture moisture susceptibility before stripping occurs. $L C_{S N}$ is found as expressed in Eq. (4)

$L C_{S N}=N_{d} e^{\left(-\frac{\beta+1}{\beta}\right)}$

Mixtures with higher $L C_{S N}$ values are expected to have better resistance to stripping before stripping occurs as compared to those with lower $L C_{S N}$ values. Mixtures that do not show a stripping phase in the HWTT are considered to have a robust resistance to stripping, with $L C_{S N}$ values larger than the number of load cycles applied during the test

To quantify mixture performance in terms of rut depth accumulation due to stripping, the parameter Stripping Life $\left(L C_{S T}\right)$ is proposed. It represents the number of additional load cycles after $L C_{S N}$ needed for the rut depth induced by stripping to reach $12.5 \mathrm{~mm}$. Accordingly, in this study, $L C_{S T}$ was calculated as Eq. (5). Mixtures with higher $L C_{S T}$ values are expected to have better resistance to stripping after stripping occurs.

$L C_{S T}=L C_{12.5}-L C_{S N}$

where, $L C_{12.5}=$ number of load cycles at 12.5 rutting

Rutting resistance evaluation. The Tseng-Lytton model [Tseng and Lytton, 1989] is employed to fit the viscoplastic strain data before the onset of stripping at the SN, as shown in Equation (6):

$\varepsilon^{v p}=\varepsilon_{\infty}^{v p} \exp \left[-\left(\frac{\alpha}{L C}\right)^{\lambda}\right]$ 
Where, $\varepsilon_{\infty}^{v p}, \alpha$ and $\lambda=$ model coefficients

$\varepsilon_{\infty}^{v p}, \alpha$, and $\lambda$ are determined from a non-linear regression analysis.

To quantify mixture resistance to rutting in the HWTT and compare different mixtures, the parameter Viscoplastic Strain Increment $\left(\Delta \varepsilon^{v p}\right)$ is proposed. This parameter is calculated as the slope of the viscoplastic strain versus load cycle curve at a certain number of 10,000 load cycles, as described in Eq. (7)

$\Delta \varepsilon_{10000}^{v p}=\alpha^{\lambda} \lambda \varepsilon_{\infty}^{v p} \exp \left[-\left(\frac{\alpha}{10000}\right)^{\lambda}\right] 10000^{-(\lambda+1)}$

Asphalt mixtures with higher $\Delta \varepsilon_{10000}^{v p}$ values are expected to be more susceptible to rutting than those with lower $\Delta \varepsilon_{10000}^{v p}$ values.

(a)

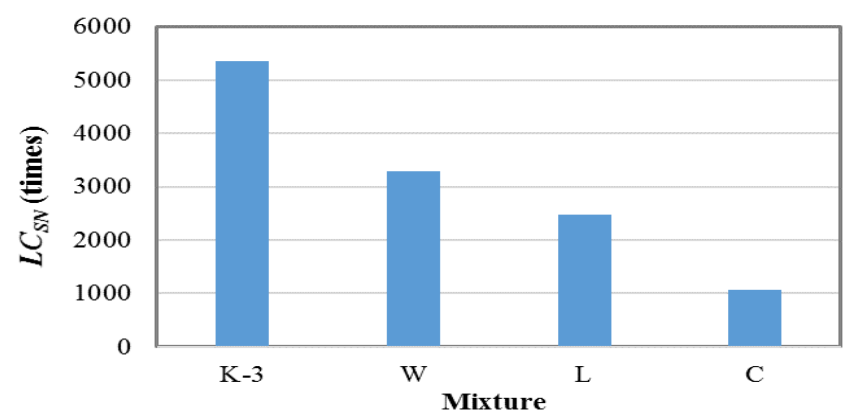

(b)

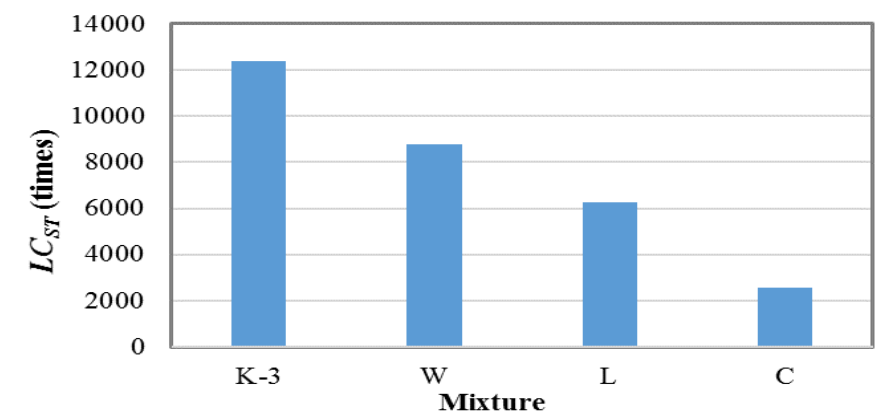

(c)

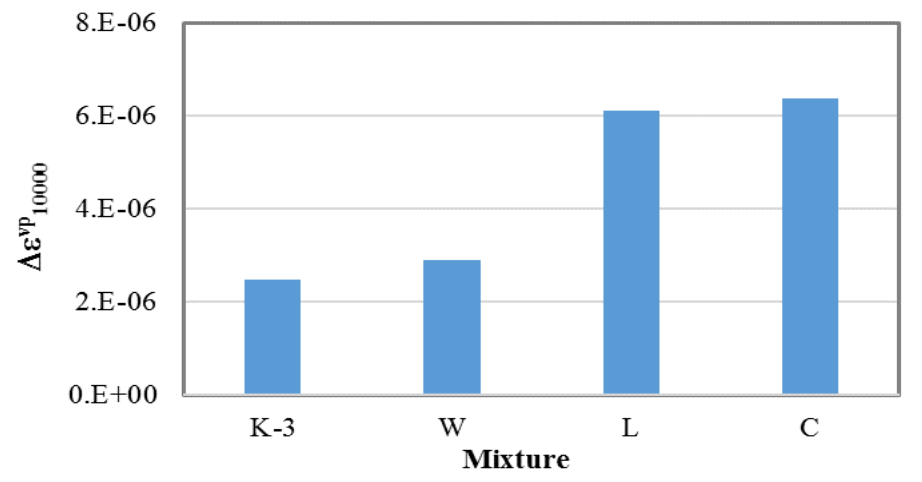

Figure 3. HWTT a) $L C_{S N}$, b) $L C_{S T}$, and c) $\Delta \varepsilon_{10000}^{v p}$ Results 
$L C_{S N}, L C_{S T}$, and $\Delta \varepsilon_{10000}^{v p}$ were calculated for all mixtures and are summarized in Fig. 3. The post compaction phase usually occurs within the first 1000 load cycles as the wheel load densifies the mixture and the air voids decreases greatly [Aschenbrener and Currier 1993]. The $L C_{S N}$ value was lower than 1000 load cycles in case of controlled mix $\mathrm{C}$ indicating that stripping occurred early during the test as shown in Fig. 3(a). Since all of the mixes reach a maximum deformation of $12.5 \mathrm{~mm}$, the $L C_{S T}$ values have the same trend with $L C_{S N}$ values as compared between Fig. 3(a) and Fig. 3(b). Mixtures with higher $L C_{S N}$ and $L C_{S T}$ values are expected to have better stripping resistance, as compared to those with lower $L C_{S N}$ and $L C_{S T}$ values; and they relatively correspond with the results from ITS test. In general, the addition of either of the two anti-stripping agents in mixes $\mathrm{K}$ and $\mathrm{W}$ was able to improve asphalt mixture moisture susceptibility before and after stripping occurred. Additionally, there is also an improvement in rutting resistance with the two anti-stripping agents. The comparison between mix $\mathrm{L}$ and mix $\mathrm{C}$, indicating that limestone is able to improve moisture susceptibility; however, as seen in Fig. 3(c), they have no effect on the rutting resistance in the HWTT.

\section{CONCLUSION}

The evaluation of stripping resistance of asphalt mixtures with various additives has been done based on the visual observation in boiling water test, TSR value in ITS test, and image analysis. Moisture susceptibility and rutting resistance of asphalt mixtures were evaluated by new parameters from HWTT data analysis. Based on the statistical and analysis of results in this study, the following conclusions and recommendation are made:

- Generally, the anti-stripping agents provide a significant improvement in moisture resistance of asphalt mixture. In particular, the highest moisture resistance is obtained for asphalt mixtures modified with the anti-stripping agents, K-3, DG and W. Limestone is unqualified in the boiling water test but meets the standard of ITS test.

- The addition of anti-stripping agents significantly improve mixture stripping resistance before and after stripping occurs as well as rutting resistance. The use of limestone in recycled asphalt mixture has no pronounced effect on rutting resistance. In this study, the early-life rutting is not really the indication of rutting resistance.

- Further works into the comparison between testing data and field pavement performance data are recommended.

\section{REFERENCES}

Al-Qadi, I.L., Abuawad, I.M., Dhasmana, H., Coenen, A.R., and Trepanier, J.S. (2014). "Effects of Various Asphalt Binder Additives/Modifiers on Moisture-Susceptible Asphaltic Mixtures." Research Report FHWA-ICT-14-004. University of Illinois. Urbana.

Aschenbrener, T., and G. Currier, "Influence of Testing Variables on the Results from the Hamburg WheelTracking Device” CDOT-DTD-R-93-22. Colorado Department of Transportation, Denver (1993).

ASTM D3625-96. (2005). "Effect of Water on Bituminous-Coated Aggregate Using Boiling Water" ASTM International, West Conshohocken, PA.

Harikrishnan, K. (2008). "Evaluation of indirect tensile strength as design criteria for Superpave mixtures." ProQuest LLC, North Carolina.

Korea Standard (KS) F 2398 (2012). "Testing method for resistance of compacted asphalt mixtures to 
moisture induced damage." Korea Technology Center, Seoul, Korea.

Little, D.N. and Epps, J.A. (2001). “The benefits of hydrated lime in hot mix asphalt.” The Versatile Chemical. National Lime Association, Arlington, Virginia.

Rahman, S. (2012). "The way to resist moisture damage and rutting in asphalt mixture in Bangladesh by the application of hydrated lime." IOSR Journal of Mechanical and Civil Engineering, 3, 36-40

Solaimanian, M., Harvey, J., Tahmoressi, M., and Tandon, V. (2003). "Test Methods to Predict Moisture Sensitivity of Hot-Mix Asphalt Pavements." Moisture Sensitivity of Asphalt Pavements: A National Seminar, San Diego, California

Solaimanian, M., Kennedy, T. W., Elmore, W. E. (1993). "Long-term evaluation of stripping and moisture damage in asphalt pavements treated with lime and anti-stripping agents." Report CTR 0-1286-1F, TxDOT, University of Texas, Austin, TX.

Taylor, M.A. and Khosla, N.P. (1983). "Stripping of Asphalt Pavements: State of the Art." Transportation Research Record 911, Transportation Research Board, Washington, D.C.

Tex-242-F. (2014). “Test procedure for Hamburg Wheel Tracking test” TxDOT, Austin, TX.

Tseng, T.H., and Lytton, R.L. (1989). "Prediction of Permanent Deformation in Flexible Pavement Materials" Implication of aggregates in the design, construction, and performance of flexible pavements, ASTM, West Conshohocken, PA, 154-172.

Yin, F., Arambula, E., Lytton, R., Martin, A.E., and Cucalon, L.G. (2014). "Novel Method for Moisture Susceptibility and Rutting Evaluation Using Hamburg Wheel Tracking Test" Journal of the Transportation Research Board, 2446, 1-7.

Walubita, L.F., Faruk, A.N.M., Zhang, J., Lee, S.I., and Simate, G.S. (2016). "The Hamburg Rutting Test: Alternative Data Analysis Methods and HMA Screening Criteria." 95 ${ }^{\text {th }}$ TRB Annual Meeting, Washington D.C. 